W. J. Taylor MD, M. C. Champion MB FRCPC, A. W. Barty MD FRCPC, J. B. Hurtig, MD FRCPC

\title{
Measuring gastric contents during general anaesthesia: evaluation of blind gastric aspiration
}

\begin{abstract}
Various medications have been reported to decrease gastric content volume and thus risk for pulmonary aspiration. The majority of studies have used blind gastric tube aspiration of stomach contents as the method of measuring the volume of gastric contents. This study evaluated the accuracy of this method by first measuring gastric content volume using blind gastric aspiration and then aspirating residual conten in the stomach, using a visually guided flexible fiberoptic gastroscope. Ten obese patients undergoing elective surgery were studied. Gastric contents were collected using a multi-orificed gastric tube and blind aspiration. Immediately after this was completed, residual gastric volume was collected using a visually guided gastroscope. The sum of these two aspirate volumes (true total gastric volume) was statistically compared with the blind aspirate volume. The blind aspirate volume underestimated true total gastric volume by an average of $14.7 \mathrm{ml}$ and was significantly different from true total gastric volume $(p<0.05)$. Blind gastric aspiration was thus demonstrated only to approximate true gastric volume. Its use to measure precisely gastric volume cannot, therefore, be recommended.
\end{abstract}

\section{Key words}

GASTROINTESTINAL TRACT: stomach, contents.

From the Department of Anaesthesia and Division of Gastroenterology, Ottawa Civic Hospital and the University of Ottawa, Ottawa, Ontario.

Address correspondence to: Dr. W. J. Taylor, Department of Anaesthesia, C 3, Ottawa Civic Hospital, 1053 Carling Avenue, Ottawa, Ontario, K1Y 4E9.
The importance of gastric content volume as a determinant of risk for gastric aspiration has long been discussed. ${ }^{1,2}$ Since Roberts and Shirley's study published in $1974,{ }^{\prime}$ many authors have quoted a gastric content volume of greater than $0.4 \mathrm{ml} \cdot \mathrm{kg}^{-1}$, or $25 \mathrm{ml}$ for most adult patients, as a risk factor for serious sequelae of pulmonary aspiration of gastric contents.

Many trials have been carried out examining the ability of various preoperative medications such as $\mathrm{H}_{2}$ receptor blockers, anticholinergics, and metoclopramide to reduce gastric volume. ${ }^{3-8}$ The most common method of measuring gastric volume in these studies has been blind gastric tube aspiration of stomach contents.

Unfortunately, there are conflicting views on the validity of this technique of gastric volume measurement. Some authors believe that blind aspiration of stomach contents with a gastric tube consistently underestimates true gastric content volume ${ }^{9-10}$ However, a recent study has reported that blind aspiration accurately estimates true gastric content volume. ${ }^{\text {" }}$ Because of these differing opinions, we believe that this common method of gastric volume measurement warrants further evaluation.

This study prospectively examined the accuracy of blind aspiration in measuring gastric content volume by using a visually guided flexible fiberoptic gastroscope.

\section{Methods}

The study was approyed by the Hospital Ethics Committee. Ten patients, six female and four male, between the ages of 24 and 72 were studied. All were at least 30 per cent above ideal body weight as defined by insurance company ideal weight tables. ${ }^{12}$ The nature and purpose of the study were explained and informed consent was obtained before inclusion in the study. Patients undergoing elective general or gynaecological surgery using general anaesthesia with tracheal intubation were studied. Those with a history of upper gastrointestinal disease or past history of gastric surgery, those with anatomical anomalies that would lead to technical problems in gastric tube placement or use of the gastroscope (for example 
TABLE 1 Results: accuracy of gastric volume measurements

\begin{tabular}{lllll}
\hline Patient & $\begin{array}{l}\text { Blind ASP } \\
\text { volume }(\mathrm{ml})\end{array}$ & $\begin{array}{l}\text { Residual } \\
\text { volume }(\mathrm{ml})\end{array}$ & $\begin{array}{l}\text { TTGV } \\
(\mathrm{ml})\end{array}$ & $\begin{array}{l}\text { BAPTV } \\
\%\end{array}$ \\
\hline $\mathrm{I}$ & 29.0 & 11.0 & 40.0 & 72.5 \\
2 & 8.0 & 20.5 & 28.5 & 28.1 \\
3 & 23.0 & 16.0 & 39.0 & 59.0 \\
4 & 6.0 & 4.0 & 10.0 & 60.0 \\
5 & 3.0 & 12.5 & 15.5 & 19.4 \\
6 & 21.0 & 10.0 & 31.0 & 67.7 \\
7 & 12.0 & 10.0 & 22.0 & 54.5 \\
8 & 85.0 & 19.0 & 104.0 & 81.7 \\
9 & 53.0 & 21.0 & 74.0 & 71.6 \\
10 & 7.0 & 23.0 & 30.0 & 23.3 \\
& & & & \\
Average & 24.7 & 14.7 & 39.4 & 53.3 \\
SD & 24.6 & 5.8 & 27.2 & 21.2 \\
\hline
\end{tabular}

TTGV = true total gastric volume $=$ Blind ASP + Residual. BAPTV $=$ Blind ASP per cent of true volume $=$ Blind ASP/TTGV (\%).

oesophageal strictures) and any patients taking medications known to alter upper GI tract motility or $\mathrm{pH}$, were excluded from the study.

All patients were kept fasting on the day of surgery. They received $2 \mathrm{mg}$ of lorazepam sublingually, $60-90$ minutes preoperatively. On arrival in the operating room an intravenous infusion of lactated Ringer's solution was begun and fluids were administered as needed. Standard anaesthetic monitoring systems were used. All patients were then given 50-125 $\mu \mathrm{g}$ of fentanyl followed by a defasciculating dose of d-tubocurarine $3.0-4.5 \mathrm{mg}$. Induction of anaesthesia was then accomplished using thiopentone $3-5 \mathrm{mg} \cdot \mathrm{kg}^{-1}$, and the patients were paralysed with succinylcholine $1.5-2.0 \mathrm{mg} \cdot \mathrm{kg}^{-1}$ to aid tracheal intubation. Anaesthesia was maintained with a combination of nitrous oxide, oxygen and jsoflurane. Supplemental narcotics were given as judged necessary by the attending anaesthetist.

As soon as the patient was intubated and stabilized after induction, a multiorificed 16 Fr Salem Sump tube (Argyle Co, St. Louis, Mo.) was passed orally, to avoid epistaxis, by the same member of the research team in each case. Position in the stomach was confirmed by auscultation over the gastric area of an injected air bolus through the gastric tube and by aspiration of typical gastric contents. With the tip of the gastric tube approximately $60-70 \mathrm{~cm}$ distal to teeth, the tube was aspirated using wall suction at a negative pressure ranging from 25 to $40 \mathrm{~mm} \mathrm{Hg}$. Attempts to maximize gastric fluid aspirate volume were made by continuing aspiration intermittently as the tube was slowly withdrawn with a rotating motion. The gastric aspirate was collected in an in-line collection container, and measured later using a graduated cylinder. Once no further aspirate could be obtained the gastric tube was removed. A flexible fiberoptic gastroscope (either FUJINon FUL-300 or Olympus CLV) was then passed into the stomach by an experienced endoscopist. All residual gastric juices were then aspirated under direct vision using wall suction and an in-line collection device.

This residual volume was then measured immediately in a graduated cylinder. The true total gastric content volume was then calculated for each patient by adding the blind aspirate volume to the residual volume.

The paired sample $t$ test was used to evaluate the difference between the blind gastric tube aspiration volume and true total volume obtained. The level of statistical significance accepted was $p \leq 0.05$.

\section{Results}

The average weight of our study group was 101.2 \pm $10.6 \mathrm{~kg}$. Gastric content volume measurements are shown in the Table. The gastric content volume aspirated blindly, using a gastric tube (Blind ASP), varied from $3 \mathrm{ml}$ to $85 \mathrm{ml}$ (mean $\pm \mathrm{SD}=24.7 \pm 24.6 \mathrm{ml}$ ). The residual content volume left in the stomach after blind aspiration (Residual Vol) and collected using the visually guided gastroscope varied from $4 \mathrm{ml}$ to $23 \mathrm{ml}$ (mean $\pm \mathrm{SD}=14.7 \pm 5.8 \mathrm{ml}$ ). Nine out of ten patients had at least $10 \mathrm{ml}$ remaining in the stomach after blind gastric tube aspiration. The true total gastric volume (TTGV = Blind ASP + Residual Vol), varied from $15.5 \mathrm{ml}$ to $104 \mathrm{ml}$ (mean $\pm \mathrm{SD}=39.4 \pm$ $27.2 \mathrm{ml}$ ). The percentage of the true total gastric volume represented by the blind aspirate volume (BAPTV) varied from 19.4 to 81.7 per cent (mean $\pm \mathrm{SD}=53.3 \pm 21.2 \mathrm{per}$ cent). There was a statistically significant difference between the volume obtained by blind gastric tube aspiration (Blind ASP) and the true total gastric volume (TTGV), $(p<0.05)$.

\section{Discussion}

Several studies have examined the accuracy of blind gastric aspiration. Holdsworth concluded that blind gastric aspiration failed to empty the stomach of its contents in a reliable fashion. ${ }^{10}$ In a report by Ong, blind gastric aspiration was shown to underestimate true total gastric volume which was measured using polyethylene glycol (PEG) dilution. ${ }^{9}$ Recently though, Hardy concluded that blind gastric aspiration of stomach contents was a very good estimate of true total gastric volume. ${ }^{11}$

These conflicting conclusions may be explained by the various techniques that were used to measure true total gastric volume. These studies probably overrated the accuracy of blind gastric aspiration by using methods of measurement which themselves underestimated true total 
gastric volume. In Ong's work, blind aspirate volume was compared with the apparent true total gastric volume which was derived using PEG dilution. ${ }^{9}$ Although believed to be a fairly accurate estimate of gastric volume, the PEG dilution technique has been postulated to underestimate true gastric volume. ${ }^{13}$ In Hardy's study, blind aspiration was at first used to withdraw as much gastric volume as possible. A surgeon then manually inspected the stomach in order to ascertain if complete gastric emptying had occurred. After the stomach had been manually inspected, the gastric pouch was mobilized, and any further residual gastric volume was aspirated blindly. True total gastric volume was taken as the sum of the original aspirated volume and the residual volume obtained after manual inspection of the stomach. However, we feel that complete collection of residual volume could not be guaranteed in this study, despite the use of manual inspection, since blind instead of direct visually guided aspiration was used. Hence, the overall true total gastric volume would be underestimated. The original blind aspiration volume would thus falsely appear to be a more accurate estimate of true total gastric volume than in reality.

In our study, blind gastric aspiration was followed immediately by direct inspection of the stomach contents using a gastroscope. Any residual volume left after blind aspiration was withdrawn under visual guidance with the gastroscope. The sum of the blind aspirate volume and this residual volume was reported as the true total gastric volume. We believe that direct visualisation and aspiration with a gastroscope is a more accurate method of residual gastric volume measurement than those used in previous studies. With direct visualisation of the stomach lumen, full evacuation of gastric contents could be guaranteed thus minimizing the risk of true total gastric volume underestimation.

Our results show that blind aspiration merely provides a fair estimate of true total gastric volume. We demonstrated that blind aspiration significantly underestimated true total gastric volume. This underestimation averaged $14.7 \mathrm{ml}$ compared with only $4.4 \mathrm{ml}$ in Hardy's study. ${ }^{11}$

We conclude that blind gastric aspiration significantly underestimates true gastric volume but can be used to obtain a fair estimate of gastric volume. The residual volume left by this technique may not always be clinically important in terms of risk for aspiration. However, our results clearly show that blind aspiration cannot be recommended for the accurate measurement of gastric volume. Aspiration using a visually guided gastroscope should probably be reserved as the method of choice when precise measurement of gastric volume is needed.

\section{Acknowledgement}

Our thanks for statistical consultation to the Department of Epidemiology at the Health Sciences Centre, University of Ottawa.

\section{References}

1 Roberts RB, Shirley $M A$. Reducing the risk of acid aspiration during cesarean section. Anesth Analg 1974; 53: 859-68.

2 James CF, Modell JH, Gibbs CP, Kuck EJ, Ruiz BC. Pulmonary aspiration - effects of volume and $\mathrm{pH}$ in the rat. Anesth Analg 1984; 63; 665-8.

3 Coombs DW, Hooper D. Colton T. Preanesthetic cimetidine alteration of gastric fluid volume and $\mathrm{pH}$. Anesth Analg 1979; 58: 183-8.

4 Morison DH, Dunn GL, Fargas-Babjak et al. A double blind comparison of cimetidine and ranitidine as prophylaxis against gastric aspiration syndrome. Anesth Analg 1982; 61: 988-92.

5 Manchikanti L, Marrero TC, Roush J. Preanesthetic cimetidine and metoclopramide for acid aspiration prophylaxis in elective surgery. Anesthesiology 1984; 61: 48-54.

6 Solanki DR, Suresh $M$, Ethridge $H E$. The effects of intravenous cimetidine and metoclopramide on gastric volume and pH. Anesth Analg 1984; 63: 599-602.

7 Rao TLK, Madhavareddy S, Chethagada M, El-Etr AA Metoclopramide and cimetidine to reduce gastric fluid pH and volume. Anesth Analg 1984; 63: 1014-6.

8 Cohen SE. Jasson J, Talafre M, Chauvelot-Moacheon L, Barrier $G$. Does metoclopramide decrease the volume of gastric contents in patients undergoing cesarean section? Anesthesiology 1984; 61: 604-7.

9 Ong BY, Palahniuk RJ, Cumming $M$. Gastric volume and $\mathrm{pH}$ in out patients. Can Anaesth Soc J 1978; 25 : 36-9.

10 Holdsworth JD, Furness RMB, Roulston RG. A comparison of apomorphine and stomach tubes for emptying the stomach before general anaesthesia in obstetrics. $\mathrm{Br} J$ Anaesth 1974; 46: 526-9

11 Hardy I, Plourde G, Lebrun M, Coté C, Dubé S, LePage $Y$. Determining gastric contents during general anaesthesia: evaluation of two methods. Can Anaesth Sac J 1987; 34: 474-7.

12 Desirable weights of adults. Society of Actuaries and Association of Life Insurance Medical Directors of America, 1980.

13 Ivey $K$, Schedl $M$. Gastric nonabsorbable indications for studies in man. Gastroenterology 59: 234-9. 


\section{Résumé}

Plusieurs médicaments ont été incriminés dans la diminution du volume du contenu gastrique et ainsi des risques d'aspiration pulmonaire. La majorité des études ont utilisé l'aspiration du contenu gastrique par un sube placé aveuglément comme méthode de mesure du volume gastrique. Cette étude évalue l'exactitude de cette mêthode en mesurant initialement le volume du contenu gastrique par aspiration à travers un tube gastrique placé à l' aveugletse puis aspirant le contenu gastrique résiduel utilisant un gastroscope fibroptique. Dix patients obèses devant subir une chirurgie élective ont étéétudiés. Le contenu gastrique a été collecté utilisant un tube gastrique à plusieurs orifices et une aspiration aveugle. Immédiatement après ceci, le contenu gastrique résiduel fut mesuré par aspiration à travers le gastroscope. La somme de ces deux volumes aspirés (représentant le vrai volume du contenu gastrique) a été statistiquement comparée au volume aspiré aveuglément. Le volume aspiré aveuglément sous-estimait le volume gastrique tatal en moyenne de $14.7 \mathrm{ml}$ et était significativement différent du volume gastrique total $(p<0.05)$. L'aspiration gastrique aveugle donne ainsi une approximation du volume gastrique total. Son utilisation pour mesurer exactement le volume gastrique ne peut donc être recommandée. 